\section{Ética feminista \\ y feminismo \\ de la igualdad}

\author{
María Elena León \\ Rodríguez*
}

\section{RESUMEN}

Este artículo aborda la ética feminista desde la perspectiva del feminismo de la igualdad. Esboza las resistencias teóricas e ideológicas que están implícitas en una ética femenina y propone, en su lugar, una ética feminista basada en una hermenéutica crítica feminista.

\section{DESCRIPTORES BÁSICOS}

Filosofía, Ética Feminista, Feminismos, Igualdad, Diferencia.

\section{ABSTRACT}

This paper approaches the feminist ethics from the perspective of the Feminism of Equality. It outlines the theoretic and ideological resistances implied in feminine ethics and proposes a feminist ethics based on a hermeneutic feminist criticism, instead.

* Licenciada en Filosofía, Universidad de Costa Rica. Profesora de Filosofía en Universidad Estatal a Distancia, Universidad de Costa Rica e Instituto Tecnológico de Costa Rica.

Rec. 28-02-07 Acep. 18-10-07

\section{KEYWORDS}

Philosophy, Feminist Ethics, Feminisms, Equality, Difference

\section{Perspectivas del feminismo de la igualdad}

El debate de la ética feminista se ha centrado en la polémica entre la igualdad y la diferencia, esta última toma sus marcos teóricos del feminismo francés e italiano (Cavana, 1995). El feminismo de la igualdad exige una igualdad tanto en derechos legales como oportunidades desde un punto de vista formal, puesto que el sistema despliega ciertos mecanismos que recortan las posibilidades reales de las mujeres para alcanzarlos, en tanto el feminismo de la diferencia parte del enunciado que subraya la crisis del sujeto. El sujeto, de acuerdo con el feminismo propuesto por Rodríguez (filósofa española de la diferencia), desaparece porque trataba de promover una hegemonía de un idealismo cultural sin ningún referente real.

Los estudios feministas examinan el concepto de diferencia desde tres perspectivas: el punto de vista patriarcal, la teoría de los feminismos de la diferencia y el punto de vista de los feminismos materialistas. El punto de vista patriarcal señala la concepción androcéntrica de la 


\section{ESPIGA}

diferencia sexual entendida como inferioridad y esencia. Los feminismos de la diferencia retoman la diferencia como paradigma de la supuesta identidad femenina. Y por último, los feminismos materialistas parten de la realidad empírica de la diferencia de las mujeres para analizar la explotación femenina.

Como se dijo anteriormente, la diferencia desde el punto de vista patriarcal se define como inferioridad, es decir, una desigualdad de valores en donde las mujeres son interpretadas como faltas de ser. Aristóteles (1980) es el filósofo que desarrolló esta definición negativa de la diferencia entre los sexos, al mantener una concepción de opuestos que legitima la jerarquía de lo masculino sobre lo femenino. Este poder masculino derivado de lo biológico tiene consecuencias importantes en el ámbito político, creando espacios y relaciones según el sexo en términos de desigualdad.

La otra noción negativa de diferencia descansa en la explicación del carácter sexual como cualidades sexuales psicológicas que corresponden a las fisiológicas. Este carácter sexual tiene como fin promover la diferencia sexual entre los géneros para institucionalizar una esencia propia de cada sexo. A Rousseau se le nombra como uno de los defensores de la teoría de la complementariedad sexual porque describe un plan educacional basado en las diferencias sexuales. Estas dos interpretaciones negativas de la diferencia sexual parten de la premisa falsa de identificar lo masculino con lo humano en general.

En cuanto a las nociones positivas de la diferencia, se mencionan las posiciones de los feminismos de la diferencia. En general, estos feminismos creen que sólo afirmando las diferencias se puede conseguir la libertad femenina. A continuación voy a mencionar algunas ideas importantes de cada uno de ellos: Lucy Irigaray, el feminismo italiano (Grupo de filósofas Diotima) y las propuestas de la ética del cuidado (Carol Gilligan).

\section{Resistencias teóricas e ideológicas}

Lucy Irigaray es la representante del feminismo francés de la diferencia y relaciona el concepto de la diferencia de Deleuze y Derrida con la teoría de Lacan. Según esta filósofa francesa, la sexualidad femenina ha sido pensada a partir de parámetros masculinos y no deja de ser un soporte complaciente de la "puesta en acto de los fantasmas del hombre" (1982:24). La sexualidad ha sido analizada desde la economía de lo Mismo (1982:72), desde la reducción de lo otro a lo Mismo, y así ha 
borrado la diferencia de los sexos al inducir un único patrón de comportamiento sexual.

Irigaray observa que no se trata de elaborar una nueva teoría en la que la mujer sería el sujeto o el objeto sino, más bien, examinar la maquinaria teórica misma para eliminar la idea de que es posible una verdad y un sentido unívoco. Además, llama a las mujeres a no participar en movimientos que pretendan invertir la estructura de dominio, pues es necesario desbaratar la estructura de los sistemas lógicos en lugar de favorecerlos con la participación de las mujeres en las instituciones patriarcales.

Esta feminista cree que si las mujeres luchan por la igualdad de derechos podrían llegar a ser hombres en el futuro y "la mujer debería (...) guardar y mantener lo que se denomina la feminidad" (1982:80). No la feminidad impuesta por el sistema de representación de hombres sino la que se da en relación consigo misma y con las demás mujeres. Estas relaciones con otras mujeres facilitarían la producción de otro orden, además del masculino; orden estrictamente femenino que hable del goce de las mujeres.

La feminidad existente es producto de una mascarada (1982:80), una función, una imagen, un valor impuesto a las mujeres desde la representación masculina. En esta mascarada las mujeres "se someten a la economía dominante del deseo, para tratar de permanecer por lo menos en el 'mercado'"' (1982:128). De esta forma, las mujeres pierden contacto consigo mismas y se subordinan al deseo y al lenguaje masculino, y de lo que se trata es de articular estos dos deseos y estos dos lenguajes para propiciar un diálogo entre ambos.

En cuanto a la feminidad, Irigaray sostiene que no existe la mujer como genérico ni se le puede nombrar en un sentido propio. Sin embargo, esta filósofa hace residir el valor de una mujer en la maternidad (1982:80) por cuanto la sexualidad determina el ser mujer y las diferencias. Cabe preguntarse si la sexualidad no es también producto del mismo sistema de representaciones masculinas que objetivizan el ser mujer a partir de sus relaciones sexuales.

En esta misma línea de pensamiento, el feminismo italiano de la diferencia, representado en este caso por Luisa Muraro y Carla Lonzi, plantea que la única forma de liberación femenina es a través de la autoconciencia de los grupos de mujeres. El colectivo femenino debe expresar su propio sentido de existencia y criticar las imágenes que el hombre ha creado para definir a las 


\section{ESPIGA}

mujeres. El feminismo es el primer momento político de crítica histórica a la familia y a la sociedad ya que "desmentir la cultura significa desmentir la valoración de los hechos que constituyen la base del poder" (Lonzi, 1981:35).

En Escupamos sobre Hegel. La mujer clitórica y la mujer vaginal (1981), Carla Lonzi expresa que el problema femenino cuestiona todo lo hecho y pensado por el hombre absoluto que no piensa a la mujer como un ser humano. Según esta feminista italiana, este problema no se resuelve ni con la muerte de los hombres ni con la demanda de igualdad, pues ambas alternativas forman parte del mundo masculino donde las mujeres no tienen un lugar. La igualdad de las mujeres constituye una quimera debido a que la participación de la mujer en las instituciones patriarcales no implica un verdadero reconocimiento de su potencial.

El mundo de la igualdad es el mundo unidimensional, sostiene esta feminista italiana, en oposición al mundo de la diferencia que se caracteriza por la variedad y la multiplicidad. La diferencia, según Lonzi, "es un principio existencial que se refiere a los modos del ser humano, a la peculiaridad de sus experiencias, de sus finalidades $y$ aperturas, de su sentido de la existencia..." (1981:16). El problema de esta teoría es que la idea de igualdad no presupone la eliminación de las diferencias, porque la igualdad no implica identidad.

No obstante, las diferencias proyectan unos valores estrictamente femeninos que las mujeres deben reivindicar. Entre ellos Lonzi menciona el respeto a la existencia, el sentido de la vida y, por supuesto, la maternidad (1981:10). Lonzi considera la maternidad como el único momento en el cual la mujer se desculturiza, es decir, su conciencia se vuelve hacia sí misma, hacia los orígenes de la vida y pierde contacto con el mundo masculino pues se concentra en la existencia que crece dentro de ella.

Para Luisa Muraro la diferencia"hace diferir de sí mismo a un idéntico ser humano y lo hace ser sí mismo: mujer, hombre" (1998: 126). La diferencia sexual señala la necesidad de un trabajo simbólico no elaborado históricamente, pero importante en la conformación de la identidad humana de la sexualidad. Esta tarea simbólica se reduce al lenguaje y a la introducción de diferencias significativas que generen sentido. Entonces, la diferencia no tiene significado si no es significante (2001:78); de ahí que la función de lo simbólico sea hacer algo significante. 
El feminismo, de acuerdo con Muraro (2000), da la confianza de que las mujeres pueden conocer y transformar la realidad a partir del reconocimiento de las diferencias entre las mismas mujeres y los seres humanos en general. Así, el feminismo puede cambiar la realidad, no por medio de la organización o el poder, sino mediante las prácticas de toma de conciencia de las mujeres que dan un valor político a la subjetividad femenina. Muraro llama a esta nueva valoración de la subjetividad femenina "política de lo simbólico" (2000:46) por cuanto las mujeres han cambiado la relación que tenían con los hombres y, de esa forma, cambian la realidad.

La lucha política de las mujeres se basa en el principio de partir de la propia subjetividad femenina $\mathrm{y}$ reconocer las diferencias existentes entre las mismas mujeres. La relación entre mujeres permite revivir en el presente algún episodio de la relación infantil con la madre y volver, de alguna forma, a representar simbólicamente la relación femenina con la fuerza materna (1992:57). Este feminismo considera importante retomar a la madre como modelo simbólico para dar lugar a un simbolismo femenino autónomo.
Por otra parte, Carol Gilligan en su libro La moral y la teoría. Psicología del desarrollo femenino (1985), considera que los diversos estudios acerca del desarrollo moral excluyen a las mujeres y centran su atención en sujetos masculinos, de los cuales se extrae un único patrón de moralidad aceptable. Sin embargo, esta autora supone la presencia de dos voces o modos diferentes de hablar sobre problemas morales, o dos modos de describir la relación entre el yo y el otro. En esta dinámica, las voces femeninas tienen algo que decir pese a las omisiones o a la ausencia sospechosa de éstas en los estudios e investigaciones sobre el desarrollo moral.

El objetivo de Gilligan en esta obra es extender la comprensión del desarrollo humano tomando en cuenta la participación de las mujeres en la construcción de la teoría, con el fin de generar las bases para una nueva teoría moral que dé una visión más general de las vidas de los dos sexos. Es así como Gilligan presenta lo que ella llama una ética del cuidado o ética de la responsabilidad, la cual brota de una conciencia de la interconexión, es decir, de la experiencia de la relación entre personas: "El ideal de cuidado y atención es, por tanto, una actividad de relación, de ver y responder a la necesidad, de cuidar al mundo sosteniendo la 


\section{ESPIGA}

red de conexión para que nadie se quede solo" (1985:109).

Usualmente, las investigaciones acerca del desarrollo humano asumen la vida del hombre como norma y tratan de crear mujeres a su imagen. Esta tendencia a proyectar una imagen masculina se remonta a Freud, quien previno del fallo en el desarrollo de las mujeres. Según Freud, la naturaleza habría privado a las mujeres de la energía necesaria para resolver el complejo de Edipo. Por ende, el superego femenino no es tan independiente de sus orígenes emocionales como lo es el del hombre. Como resultado, las mujeres no tienen el mismo sentido de la justicia que los hombres y son más propensas a evadir las exigencias de la vida y a refugiarse más en los sentimientos que en los juicios.

Más tarde, Nancy Chodorow atribuye las diferencias entre los sexos al hecho de que las mujeres son educadas para servir a los demás y esto hace que las vivencias de la infancia sean diferentes y se interpreten en la vida adulta de igual forma, diferentes. La personalidad femenina se define en relación y conexión con otras personas; las niñas desarrollan una empatía que las determina a experimentar las necesidades y sentimientos de los otros como si fueran propios: "las mujeres, en cuanto a madres, producen hijas con capacidad y deseos de ejercer de madres" (1984:18).

Entonces, la masculinidad es definida por medio de la separación, mientras que la femineidad es definida por el apego y se ve amenazada por la separación. Por esto, los hombres suelen tener problemas con las relaciones y las mujeres con la individuación, demostrando con ello una imposibilidad de autodefinirse e independizarse. Este miedo a la separación lleva a la falla del desarrollo moral femenino pues les imposibilita desarrollar un sentido legal indispensable para el desarrollo moral adulto. De esta forma, el modelo masculino es el mejor porque satisface las exigencias de la sociedad de consumo actual. Por el contrario, de acuerdo con Gilligan, las mujeres tienden más a la sensibilidad y a la atención de los sentimientos de los demás, tendencia obsoleta en nuestra época e innecesaria para el éxito profesional.

Si la teoría del desarrollo añade a sus interpretaciones el punto de vista de las mujeres, se discerniría el desarrollo moral femenino que obviamente existe, así como las diferencias en la interpretación de las relaciones sin tener que recurrir a una estructura jerárquica de estas diferencias. Por supuesto: “Las imágenes contrastantes de jerarquía $y$ red en el pensamiento infantil 
acerca de conflicto moral y elección iluminan dos visiones de moralidad que son complementarias, no secuenciales ni opuestas" (1985: 63).

La moral femenina se caracteriza por el autosacrificio y un poder para juzgar el egoísmo. Esta ética del autosacrificio se contrapone al concepto de derechos exigidos desde siempre por las feministas que abogan por una igualdad y una sociedad más justa. Es así como surge una tensión entre la moral de derechos que disuelve los vínculos naturales para favorecer pretensiones individuales, y una moral de la responsabilidad que tiende a establecer redes de relaciones, desdibujando la distinción entre el Yo y los otros mediante la representación de su interdependencia.

Por último, cabe señalar el análisis materialista de la diferencia. La diferencia desde el punto de vista de los feminismos materialistas es una realidad empírica (se manifiesta en la vida concreta de un modo material), una forma lógica (una forma de razonar) y una actitud política (en tanto se presenta como un proyecto). La diferencia se muestra en un contexto social, cultural, económico y político en donde las mujeres no poseen los mismos derechos que los hombres. La diferencia de las mujeres constituye su propia condición de grupo oprimido, en tanto enuncia una regla o una norma de conducta universal que permite la dependencia y la dominación masculina.

El feminismo de la igualdad o feminismo ilustrado denuncia las diferencias de género como construcciones de la razón patriarcal. Esta razón asigna espacios a las mujeres desde valores considerados esencialmente femeninos, contrapuestos a los valores masculinos analogados con el genérico humano. No se toma en cuenta que es el mismo hombre quien ha inventado las diferencias y se acepta como "lógica" esta construcción patriarcal.

Es de notar que las críticas acerca de la viabilidad de la igualdad no tienen fundamentos sólidos, si se interpreta la igualdad como anulación de diferencias. Al respecto, Amorós (filósofa española) insiste en que"el concepto de igualdad se refiere a un cierto tipo de relación entre los individuos, justamente a una relación de homologación o ubicación en un mismo rango de sujetos que son diferentes y perfectamente discernibles" (1997: 430). De igual forma, otra filósofa española, Valcárcel, sostiene que el feminismo ilustrado no separa igualdad-diferencia, aunque suele interpretarse como discurso de la igualdad. La vindicación legal o social no implica la indistinción de sujetos (1991). 


\section{ESPIGA}

El feminismo de la igualdad formula una igualdad real de libertades, porque si los sexos son diferentes, es obvia la diversidad entre los seres humanos, sin que esto implique la desigualdad. La igualdad es una idea normativa, por consiguiente, es un valor. La igualdad se construye y se valora como pertinente al constatar la importancia de su aplicabilidad en la vida de las mujeres.

Precisamente, el feminismo ilustrado parte de la crítica de la supuesta universalidad y los presupuestos patriarcales ilustrados. Esa falsa universalidad convoca a las feministas a la desmitificación del sujeto masculino de la razón, y para eso utiliza la capacidad crítica de distanciamiento, de objetivación y de redefinición de los discursos hegemónicos.

Por consiguiente, el feminismo de la igualdad define a la mujer como un constructo socio-cultural producto de la educación, y no una diferencia que haya que afirmar como valor, como es el caso del feminismo de la diferencia. En palabras de Tommasi, "no hay una especificidad femenina que valorar, hay solo una desigualdad que superar respecto al hombre, una inmanencia que debe cambiarse en trascendencia" (2002: 188). La inmanencia implica una esencia femenina que corresponde a un ideal de lo que podría ser una mujer. Al exaltar las construcciones patriarcales del cuerpo femenino (mujer como madre, portadora de vida y de una ética del cuidado), o al tratar de definir la subjetividad femenina desde estos parámetros, esas construcciones no hacen más que legitimar el mismo sistema patriarcal, pues reducen a las mujeres a la vulnerabilidad, la pasividad y la resignación. En cambio, la trascendencia obliga a las mujeres a asumir su existencia y colocarse frente a los hombres como iguales, como seres humanos capaces de elegir su sexo, su profesión y sus inclinaciones.

En esta misma línea de pensamiento, Amorós establece una diferencia entre una ética feminista y una ética femenina. Por una parte, Amorós reconoce que hablar de una ética femenina es un contrasentido, debido a la universalidad implícita en los enunciados éticos (1991); por lo tanto, no tiene sentido construir un conjunto de códigos y modelos de comportamiento que solo se aplique a las mujeres:"El destinatario de una ética no puede ser sino la especie humana en cuanto comunidad de los seres racionales" (1991: 107).

Ahora bien, tampoco tiene sentido hablar de una ética con enunciados que expresen "valores femeninos" (intuición, afectividad); si bien estos valores existen en un sentido sociológico, hablar de valores 
femeninos en un sentido ético carece de significación. A pesar de ello, algunas corrientes feministas, como el feminismo de la diferencia de Irigaray, Gilligan, Muraro y Lonzi, creen en la posibilidad de una ética femenina que reivindique los valores femeninos frente a la primacía de los valores masculinos.

Esta posición es ambigua porque estos mismos valores se consideran complementarios con los femeninos, ya que quedan definidos dentro de un sistema de oposiciones determinado por construcciones sociales tanto de la mujer como del hombre. Al imponer unos valores sobre otros, se corre el riesgo de reforzar la misma opresión masculina, como sucede con la ética del cuidado defendida por Gilligan (1985), en la cual la ética masculina caracterizada por los derechos se opone a una ética femenina basada en el cuidado y el autosacrificio.

Por último, Amorós declara que la ética feminista "se plantea ante todo como crítica de la ética. No puede ser sino la denuncia de la ficción de la universalidad que se encuentra como presupuesto ideológico en la base de las distintas éticas que se han propuesto a través de la historia" (1991: 116). De esta manera, a la ética feminista le corresponde la elaboración de un nuevo concepto de universalidad y la apertura del estatuto de sujetos para las mujeres. Esta universalidad no significa la creación de un sujeto único, patrón de todos los demás, sino de un sujeto capaz de reflexionar acerca de lo que le rodea y criticar las bases de todos los discursos para "alterarlos creativamente" (Amorós, 1997:359) y promover la autonomía más que la heterodesignación.

\section{BIBLIOGRAFÍA}

Amorós, Celia, 1991. Hacia una crítica de la razón patriarcal. Anthropos, Barcelona.

1992. Feminismo y ética. En: Isegoría. Revista de Filosofía Moral y Política, número monográfico, nº6. 1994. Feminismo, igualdad y diferencia. (Edit.) UNAM, PUEG, México.

1997. Tiempo de Feminismo. Sobre feminismo, proyecto ilustrado y postmodernidad. Cátedra, Madrid.

2000. Feminismo y filosofía. (Editora) Síntesis, Madrid.

Aristóteles, 1980. Categorías. Trad. Francisco de P. Samaranch. Cuarta edición. Aguilar, Buenos Aires.

Cavana, María Luisa 1995. Diferencia. En: 10 palabras clave sobre Mujer. Celia Amorós (Directora) Tercera Edición. Verbo Divino, Navarra.

Chodorow, Nancy, 1984. El ejercicio de la maternidad. Psicoanálisis y sociología de la maternidad y paternidad en la crianza de los hijos. Trad. Óscar L. Molina. Gedisa, Barcelona.

De Beauvorr, Simone, 1972. El segundo sexo. Tomo I y II. Trad. Pablo Palant. Siglo veinte, Buenos Aires. 
Freud, Sigmund, 1980a. La disolución del complejo de Edipo. En: Obras completas. Trad. José Luis Etcheverry. Amorrortu, Buenos Aires.

1980b. Sobre la sexualidad femenina. En: Obras completas. Trad. José Luis Etcheverry. Amorrortu, Buenos Aires.

1987. Tres ensayos sobre la teoría sexual. Trad. Luis López Ballesteros y Ramón Rey. Alianza Editorial, Madrid.

Gilligan, Carol, 1985. La moral y la teoría. Psicología del desarrollo femenino. Trad. Juan José Utrilla. Fondo de Cultura Económica, México.

Irigaray, Lucy. 1978. Speculum. Espéculo de la otra mujer. Trad. Baralides Alberdi Alondo. Saltés, Madrid.

1982. Ese sexo que no es uno. Trad. Sivia Esther Tubert de Peyrou. Saltés, Madrid.

LonzI, Carla. 1981. Escupamos sobre Hegel. La mujer clitórica y la mujer vaginal. Trad. Francesc Parcerisas. Anagrama, Barcelona.

Muraro, Luisa. 1992. Sobre la autoridad femenina. Trad. Cinta Montagut. En: Birules y otros, Filosofía y género, identidades femeninas. Pamiela, Pamplona.
1998. Más allá de la igualdad. En: Sexo y esencia. De esencialismos encubiertos y esencialismos heredados: desde un feminismo nominalista. Luisa Posada Kubissa (Autora). Horas y Horas, Madrid. 1999. Signos de la diferencia. En: La identidad femenina y el discurso del derecho. Trad. Clara Jourdan. Biblos, Buenos Aires.Rivera Garretas, María Milagros. 2000. Nombrar el mundo en femenino. ICARIA, Barcelona.

Rodríguez Magda, Rosa María. 1994. Femenino fin de siglo: la seducción de la diferencia. Anthropos, Barcelona.

Rousseau, Jean Jacques. 1995. Emilio, o de la educación. Trad. Mauro Armiño. Alianza Editorial, Madrid.

Sendón de León, Victoria. 2000. ¿Qué es el feminismo de la diferencia? (Una visón muy personal).

En la internet, consultado el 6 de agosto de 2004, 3:10p.m.: http://www.creatividadfeminista.org/articulos/diferencia_sendon. htm

VAlCÁrcel, Amelia. 1991. Sexo y Filosofía. Sobre "mujer" y "poder". Anthropos, Barcelona. 